\title{
The Comparative Study of Chinese Character Teaching between Chinese as First Language and Chinese as Second Language
}

\author{
Liu Yan*, Tang Yingjuan, Cai Jing \\ College of Humanities \& Law, North China Univ. of Tech., Beijing, China \\ *Corresponding author: jljaly@163.com
}

Received December 02, 2014; Revised December 24, 2014; Accepted January 03, 2015

\begin{abstract}
Chinese character teaching as first language mainly refers to the Chinese elementary student's Chinese character literacy education in China, with the literacy teaching of low-grade students in primary school as the object of investigation. Chinese character teaching as a second language mainly refers to Chinese character teaching in teaching Chinese as foreign language, namely Chinese character teaching for non-native Chinese learners. The main purpose is to let the non-native Chinese learners can read Chinese characters and cultivate their Chinese written communication skills. This paper compares elementary school's Chinese literacy education and teaching Chinese as second language and analyzes the connection and differences between them which can improve the teaching in Chinese as a second language.
\end{abstract}

Keywords: teaching Chinese as a second language (TCSL), Chinese character teaching as first language, Chinese character teaching as second language, Comparative study

Cite This Article: Liu Yan, Tang Yingjuan, and Cai Jing, "The Comparative Study of Chinese Character Teaching between Chinese as First Language and Chinese as Second Language." American Journal of Educational Research, vol. 3, no. 1 (2015): 1-4. doi: 10.12691/education-3-1-1.

\section{Problem}

Character is the written symbol system for recording language and is the important auxiliary tool for language communication. Chinese characters as the carrier of Chinese, is one of the world's oldest written language. Due to the huge number of Chinese characters, complex structures, and various strokes, Chinese character is one of the most difficult language symbols to learn, comparing with other alphabetic writing. Therefore, the teaching of Chinese characters as first language and second language teaching is more and more taken seriously.

\section{Analysis of Characteristics of Chinese Character Teaching in Chinese as First Language}

\subsection{Teaching Content}

China's current low-grade education in primary school is mainly on literacy and simple calculation ability. Chinese character learning is the main content for lowgrade Chinese course in primary school, especially in the beginning phase. Chinese character teaching and study time account for one third of the total hours. Though Chinese character learning in primary school plays $\mathrm{s}$ an important role, it does not require students to learn a huge number of characters. Students are required to master 1740 characters which is $59.89 \%$ of 2905 characters in Chinese Characters Outline. And it is $45.59 \%$ of the 3500 characters in Frequently-used Characters of Modern Chinese which was announced by National Language Committee in March 1988. Thus it can be seen that Chinese character learning is a relatively long process. The entire six years of elementary school are based on Chinese character teaching as the center. Even in the junior middle school, the Chinese character teaching still occupies a certain weight. The Chinese character teaching in primary school is divided into two parts which are read and write. It is given priority to recognizing and memorizing Chinese characters. Writing training is complementary. These two parts are supplement to each other.

\subsection{Teaching Rules}

(1) Children's reading and writing skills are achieved step by step. Children learn Chinese characters, starting from recognizing words. Recognizing is before writing. The literacy process of children is to know some words first, but will not write. And then they can write some simple words, or words which are connected with them or they are interested in. They will be able to write more and more words after accumulation. Even in formal literacy stage, children's reading and writing skills are not entirely consistent. In 2000, the Ministry of Education issued Chinese Course Standard and also states the differences 
between read and write. It claims to recognize more and write less. Students in Grade 1-2 know 1600-1800 commonly used Chinese characters and can write 8001000 of them. Students in Grade 3-4 know 2500 commonly used Chinese characters and can write about 2500 of them. Hence, Chinese character recognition and writing are not the same thing. Being able to recognize does not mean being able to write. There should be different requirements in teaching. Recognizing and writing do not need to be in the same phase.

(2) Children learn Chinese characters by levels. They know simple structured words and words that represent specific objects or words that they are interested in first. And then it will be expanded to complex structured words, words of abstract meaning, and words that are not very related to them. Therefore, the order to master Chinese characters for children is related to the difficulty of the characters and children's life and interest.

\subsection{Teaching Method}

Children learn Chinese characters in situation which means that they learn the characters in different forms and by a lot of reading. It is actually recognizing word by using it. And writing follows the same rule too. The teaching material is very intuitive, interesting, and repeatable. A great deal of color pages are attached in the book which have intuitive image and conform to the children's psychological characteristics. At the same time, quite a number of teachers and education experts have accumulated rich experience and have flexible and varied teaching methods.

The special designed teaching method will make children acquire a huge number of characters which is the traditional literacy teaching. Chinese children's literacy education has a long history. In Western Zhou Dynasty, there were already special literacy teaching material. The best-known are Three Character Classic, The Book of Family Name, and Thousand Words and so on. The literacy teaching of the ancients has the following characteristics. First, it takes the form of concentrated literacy. Second, literacy is connected with moral education, natural knowledge, and social knowledge (Someone summed it up as "writing carry doctrine on”). Third, the literacy book mostly use verse form. Forth, it emphasizes to recite.

\section{Analysis of Characteristics of Chinese Character Teaching in Chinese as Second Language}

\subsection{The Teaching Object}

Teaching objects are adults. They know almost nothing about Chinese characters and have the impression that Chinese character is difficult to learn. Text knowledge and writing skills gained by the foreign students are mostly through learning and using of the phonetic writing. The relationship mode of words and language, the internal structure and external form of the text symbol system, and the combination form of basic word unit (such as letters of the linear array and one-sided written) all belong to the phonetic writing system. Students' skills of memory may be weaker than Chinese students. However, their ability of understanding, literacy qualification and other qualification are better.

\subsection{Teaching Content}

Chinese character radical is the important element for commonly used characters. Learning Chinese character radical is great foundation to learn Chinese characters. Most of the Chinese characters need to be remembered both the sound and meaning. This mode of recording language decides the complexity of the Chinese character structure. For foreign students who have used to simple symbol like a, b, c, d, Chinese characters are just like pictures that are not easy to depict shapes. Chinese characters do not have special notes for recording sound. According to statistics, 5631 characters of sound structure contain 1325 different notes (phonetic element). In Chinese characters, there is more than one note to record one syllable. Hence, for foreign students, most of the notes mentioned above will only be marks without the function of standing for sound. There are as many as 20 or 30 kinds of strokes in modern Chinese characters which can be divided to 6 basic strokes and 25 derived strokes. The differences among the strokes are quite small. For Foreign students, they can not find the rules to understand the differences. So it is hard for them to distinguish and hard to remember.

\section{The Comparison Between Chinese Character Teaching as First Language and as Second Language}

\subsection{The Comparison of Teaching Objects}

These two types of students' cognition of Chinese characters both start from the foundation. From the language acquisition theory, the elementary school students have already possessed the Chinese language listening and speaking skills. They have learned Chinese language's oral communication skills. However, the Chinese character can not be acquired by nature which must be learned in school and use it as written language to communicate. Non-native Chinese learners' cognition of Chinese characters also starts from the beginning which does not include learners of Chinese cultural background. Non-native Chinese learners and elementary students are in the same level based on the ability of characters. Therefore, the Chinese character teaching in Chinese as second language should follow the basic rules of Chinese character recognition.

\subsection{Comparison of Teaching Purposes}

Students who are not born in the Chinese character culture are easy to be effected by native language and thinking habits. When they are in the beginning level, it is easy for them to make mistakes in form, sound, and meaning. When they write, they either increase the stroke or decrease the stroke. They don't know that Chinese characters' form and tone can distinguish meaning and don't know there are many homophones to distinguish. Therefore, they must learn the form, sound, and meaning 
of Chinese character at the same time. In China, the literacy teaching in elementary schools also includes form, sound, and meaning. However, because children study in their native language environment, it is easier for them to know the form and meaning. The teaching focus for them should be mainly on the characteristics of word structure and let them form correct writing habit.

\subsection{Comparison of Teaching Method}

Both teaching methods seek to be vivid and interesting. The nature of Chinese character that is word itself tells the meaning and the square shapes of the character are quite suitable for this kind of teaching method. These two kinds of teaching can use contrast method to let the students recognize Chinese characters. Some Chinese characters have very similar form, close pronunciation or same pronunciation. By comparing and analyzing, and strengthening the memory of the different parts in the similar characters, students can have deeper impression of the characters and avoid mistakes which can reach good teaching effect. In addition, both teaching methods attach great importance to use Pinyin to recognize and read Chinese characters.

There are a lot differences too. First, China' primary schools use a lot of Pinyin in literacy teaching. For example, some books only use Pinyin and do not have any
Chinese characters. The books use Pinyin to tell stories to let children practice their listening and speaking. This does not have much negative effect on their Chinese character learning. However, this method is not suitable to apply in teaching Chinese as a second language.

Second, in China's primary school, when students learn new words, they can learn the character without combining it with another character. However, it is different in the Chinese character teaching as second language. When a new character is taught, a commonly used word should be used together to teach. This is teaching character and word at the same phase which can strengthen students' memory of the new character. As we know, from the perspective of the semantic units of records, Chinese characters are morpheme words. Usually, a Chinese character is a morpheme and has very strong word-building ability. Modern Chinese is mostly double syllable word that is made up of two morphemes. Hence, if you know the character, then you know the word. And if you know the word, you know the character too. The interactive relationship between Chinese character and word make them combine together closely which can get twice of the results with half of the effort.

Provide a tabular that would elucidate how Chinese Characters Teaching in Chinese as a First Language and Chinese as a Second Language converge and diverge.

Table 1. The similarities and difference between Teaching Chinese as a First language and Teaching Chinese as a Second language present the new "ideas" as a hybrid modality that may aid Teachers of Chinese as a Second Language

\begin{tabular}{|c|c|c|c|}
\hline & \multirow{2}{*}{ Similarities } & \multicolumn{2}{|c|}{ Differences } \\
\hline & & Teaching Chinese as First language & Teaching Chinese as Second language \\
\hline $\begin{array}{l}\text { Teaching } \\
\text { object }\end{array}$ & Don't know anything about Chinese characters & $\begin{array}{l}\text { Already have the oral communicative } \\
\text { competence of Chinese }\end{array}$ & $\begin{array}{l}\text { Do not have the oral communicative } \\
\text { competence of Chinese }\end{array}$ \\
\hline $\begin{array}{l}\text { Teaching } \\
\text { Purpose }\end{array}$ & $\begin{array}{l}\text { To know the basic structure units of Chinese characters } \\
\text { which are strokes and components; to acquire } 3500 \\
\text { common used characters and learn to read }\end{array}$ & $\begin{array}{l}\text { The focus is on learning character } \\
\text { pattern }\end{array}$ & $\begin{array}{l}\text { Character pattern, sound, meaning are } \\
\text { all teaching focus }\end{array}$ \\
\hline $\begin{array}{l}\text { Teaching } \\
\text { Methods }\end{array}$ & $\begin{array}{l}\text { Both teaching emphasizes } \\
\text { it to be vivid and interesting }\end{array}$ & $\begin{array}{l}\text { It uses Pinyin a lot; Do not teach } \\
\text { every new character by using the } \\
\text { method of making words }\end{array}$ & $\begin{array}{l}\text { Learning character and word } \\
\text { simultaneously }\end{array}$ \\
\hline
\end{tabular}

\section{Ideas for Teaching Chinese as a Second Language which are Inspired by Teaching Chinese as First Language}

Teaching Chinese as second language should create good language environment. Teachers should have welldesigned classroom teaching based on students' age, knowledge level, and cognitive ability. They should fully mobilize the enthusiasm of students and create a relaxed and happy classroom atmosphere.

\subsection{Strengthen Imitation and Practice}

Children's language teaching is different from other languages teaching, mainly because it exists in natural language environment which is not limited by time, location and environment. Children's imitation of language is not mechanical. They gradually understand the language rules in the process of repeating grammatically correct sentences. It is the same for Teaching Chinese characters as second language. Teachers should not only teach grammatical rules in class, but also create more chances for students to practice and combine the boring theory with real practice. By constantly imitation and practice, it will cultivate students 'language sense and enhance students' ability of language communication.

\subsection{Emphasize on Teaching in Situation}

Children's language acquisition is formed by the continuous stimulation of language information offered by the surrounding environment. Therefore, teaching Chinese characters as second language should create good language environment.

Teachers should design good classroom teaching according to students' age, knowledge level, and cognitive ability, to fully mobilize the enthusiasm of students and create a relaxed and happy classroom atmosphere. In classroom teaching, to make the student to obtain more comprehensible language input, it must create opportunities to use Chinese as much as possible for real communicative purposes. For example, teachers teach in Chinese, explain teaching materials in Chinese, organize and instruct classroom activity in Chinese, talk with students in Chinese, and organize some communicative activities among students.

\subsection{Teaching and Learning should be Step by Step, from Easy to Difficult}


When this principle is applied in Chinese character teaching, it teaches from sole character to compound word, from the stroke, stroke order, elements to whole word, from pictographs, self-explanatory characters to meaningful characters and phonogram, from most commonly used character, less commonly used character to rare used character. Different teaching methods can be used according to different types of Chinese characters which can have good foundation to analyze the elements of compound word. It can review sole word when compound word is taught.

There are connection and differences between Chinese character teaching in Chinese as first language and as second language. Compared with Chinese as first language, Chinese as second language does not take Chinese characters as the premise and foundation of Chinese learning. It uses Chinese character as an auxiliary tool for teaching and leaning Chinese. Teaching Chinese as second language can draw lessons from the teaching achievement of teaching Chinese as first language and explore more effective teaching methods.

\section{Source of Funding}

Supported by Beijing Higher Education Young Elite Teacher Project YETP1432.

\section{References}

[1] Lu Bisong (1999), Chinese Character and Chinese Character Teaching Research [M]. Beijing: Peking University Press.

[2] Zhou Jian, (2007), Theory and Method of Chinese Character Teaching [M]. Beijing: Peking University Press.

[3] Wu Yingcheng, (1991), The Relationship Between Students' Mistakes in Chinese Characters and Their Study Methods[M]. Beijing: Beijing Language Institute Press.

[4] Li Xiaoqi, Zhang Dexin. (2002). Chinese Teaching Research on Learner of English as Native Language[M]. Beijing: People's Education Press.

[5] Ellis, R. (1997) Second Language Acquisition. Oxford: Oxford University Press.

[6] Hiromi Hadley. Reviewing First and Second Language Acquisition: A Comparison between Young and Adult Learners [J]. Niigata Studies in Foreign Languages and Cultures, December 2002(No. 8), 37-48. 